\title{
Assessment of Managed Aquifer Recharge Site Suitability Using a GIS and Modeling
}

\author{
by Tess A. Russo ${ }^{1,2}$, Andrew T. Fisher ${ }^{1}$, and Brian S. Lockwood ${ }^{3}$
}

\begin{abstract}
We completed a two-step regional analysis of a coastal groundwater basin to (1) assess regional suitability for managed aquifer recharge (MAR), and (2) quantify the relative impact of MAR activities on groundwater levels and sea water intrusion. The first step comprised an analysis of surface and subsurface hydrologic properties and conditions, using a geographic information system (GIS). Surface and subsurface data coverages were compiled, georeferenced, reclassified, and integrated (including novel approaches for combining related datasets) to derive a spatial distribution of MAR suitability values. In the second step, results from the GIS analysis were used with a regional groundwater model to assess the hydrologic impact of potential MAR placement and operating scenarios. For the region evaluated in this study, the Pajaro Valley Groundwater Basin, California, GIS results suggest that about 7\% $\left(15 \mathrm{~km}^{2}\right)$ of the basin may be highly suitable for MAR. Modeling suggests that simulated MAR projects placed near the coast help to reduce sea water intrusion more rapidly, but these projects also result in increased groundwater flows to the ocean. In contrast, projects placed farther inland result in more long-term reduction in sea water intrusion and less groundwater flowing to the ocean. This work shows how combined GIS analysis and modeling can assist with regional water supply planning, including evaluation of options for enhancing groundwater resources.
\end{abstract}

\section{Introduction}

Managed recharge is an increasingly common approach for increasing groundwater supplies (Dillon et al. 2009; Maliva and Missimer 2012; O'Leary et al. 2012). Managed aquifer recharge (MAR) can use several methods, including injection wells, aquifer storage, and recovery (ASR, with injection and extraction through the same wells), and infiltration basins. Injection wells and ASR may offer advantages such as a limited land requirements, but can be technically challenging to design, have high energy and water quality requirements, and require creation and maintenance of conveyance and pumping systems (Bouwer 2002). In contrast, surface infiltration may require less engineering and result in lower operating costs than injection well or ASR systems. In this study, we use "MAR" to refer to artificial recharge through infiltration basins. Water is diverted to a natural depression or constructed retention area, where it infiltrates into the subsurface over time. MAR projects have demonstrated improvements in water quality through denitrification

\footnotetext{
${ }^{1}$ Department of Earth and Planetary Sciences, University of California, Santa Cruz, CA.

${ }^{2}$ Corresponding author: Columbia Water Center, Earth Institute, Columbia University, NY 10027; (347) 913-6835; tr2378@columbia.edu

${ }^{3}$ Pajaro Valley Water Management Agency, Watsonville, CA.

Received August 2013, accepted March 2014.

(c) 2014, National Ground Water Association.

doi: $10.1111 /$ gwat. 12213
}

during the infiltration process (Ma and Spalding 1997; Fryar et al. 2000; Schmidt et al. 2011a). These improvements can be particularly important for sites lacking reliable access to pristine surplus surface water supplies, for example, basins in which there is extensive agricultural development or widespread use of septic systems, resulting in elevated nutrient concentrations. The primary disadvantages of MAR include relatively large land area requirements, the possibility of recharging contaminated water or degrading groundwater geochemistry (Cey et al. 2008), and the challenge in identifying locations having surface and subsurface conditions amenable to infiltration.

Identifying areas suitable for MAR and estimating the influence of these projects on groundwater levels and flows can be difficult. Assessments are often made on a regional basis, within which there may be limited data on complex surface and subsurface conditions and flows. In addition, there is a need to determine how the impacts of MAR could vary with project location, size, and operating conditions. Some of these questions can be resolved through field testing, but small scale pilot field studies can be expensive and may provide limited spatial information. Computational tools can play an important role in evaluating MAR scenarios and screening potential sites, particularly because they can be applied on regional spatial scales, allow testing of operational scenarios and hydrologic conditions, and combined with other management options. 
Many hydrologic applications, including identification of locations for potential MAR projects, are well suited for geographic information system (GIS) analysis (Jha et al. 2007). Several studies have used GIS-based integration of spatial data pertinent to groundwater recharge, with data coverages being classified and weighted before combining (Saraf and Choudhury 1998; Piscopo 2001; Murray and Mcdaniel 2003; Shankar and Mohan 2005; Jasrotia et al. 2007; Chitsazan and Akhtari 2009; Yeh et al. 2009; Adham et al. 2010; Chenini et al. 2010). Methods used for classification and weighting differ greatly from study to study, due to variations in data availability, local geology, and importance of individual datasets to groundwater recharge. There is no standard set of data coverages or weights that is used in practice. Chowdhury et al. (2010) polled a group of geologists and hydrogeologists to determine a weighting system for their GIS-based recharge location assessment, and found that half the group thought equal weighting was appropriate, whereas the other half argued for variable weighting. All classification schemes are arbitrary to some extent, but methods and values can be refined over time as new data become available and individual MAR projects are tested and implemented, provided the methods used and values assigned are documented and the mapping tools remain available for later use.

Numerical modeling can also help to identify sites amenable for MAR, and can be used to estimate the potential benefits of MAR projects on regional hydrologic conditions under a range of future climate, water use, and management scenarios (Munevar and Marino 1999). Groundwater models may be combined with an optimization algorithm to test water management strategies, including artificial recharge (Abarca et al. 2006). Combining GIS-based integration methods with numerical modeling can allow a more detailed and quantitative assessment of MAR opportunities and impacts (Chenini and Mammou 2010), and can assure consistency of data used for GIS and numerical modeling studies. It is not common to link a GIS-based study of MAR suitability directly to regional modeling, but this approach can allow a quantitative assessment of MAR suitability, and a comparative evaluation of specific benefits associated with different MAR placement and operating scenarios.

Rigorous assessment of MAR suitability requires testing to determine the influence of project placement. Ultimately this involves implementation of MAR projects, but budgetary and time constraints generally limit opportunities for field-scale installations purely for testing purposes. Thus, numerical modeling can be useful in pre-implementation evaluation of project options, helping to augment an MAR suitability analysis when selecting among potential sites and operating strategies.

In this study we present a series of methods for combining GIS and numerical analyses to address the following questions: (1) How should surface and subsurface information datasets be combined to assess spatial MAR suitability? (2) How does MAR suitability vary within a basin? (3) How might hypothetical MAR operating

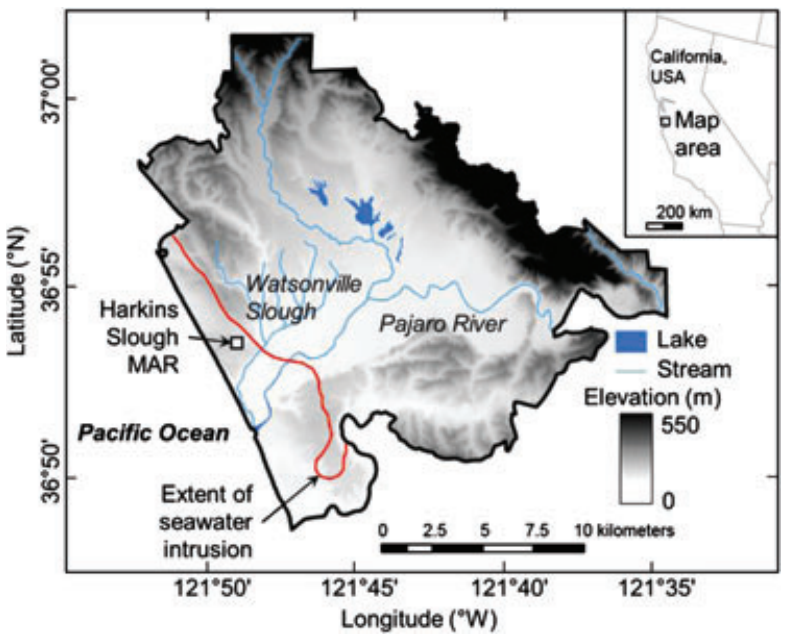

Figure 1. Location of the Pajaro Valley, California, with extent of sea water intrusion measured in 2001 (Hanson 2003), elevation, sloughs, and major streams. Area shown is the Pajaro Valley Water Management Agency's (PVWMA) boundary of operation. The Harkins Slough MAR project was established by the PVWMA and uses water diverted from the nearby Watsonville Sloughs system (Racz et al. 2011; Schmidt et al. 2011a, 2011b; PVWMA 2013).

scenarios influence groundwater conditions in the basin going forward? As an example, we apply these methods to the Pajaro Valley Groundwater Basin (PVGB), central coastal California (Figure 1), where limited groundwater resources are under considerable stress. Estimated annual overdraft in the PVGB is about $24 \%$ of annual pumpage and $10 \%$ of local precipitation. Due to chronic overdraft, a zone of sea water intrusion is advancing along much of the coastal edge of the basin (Hanson 2003; Hanson et al. 2008; Wallace and Lockwood 2009; PVWMA 2013).

\section{Methods}

\section{GIS Analysis}

We used a GIS for data management, manipulation, and analysis of 11 surface and subsurface datasets to generate a basin-wide map of "MAR suitability." As defined for this study, high MAR suitability indicates that, if a water supply of sufficient quantity and quality were available, surface and subsurface conditions are likely to be favorable for developing an MAR project. For surface analyses, primary data included: (1) surficial geology, (2) soil infiltration capacity, (3) land use, (4) elevation (topographic slope), and (5) verified (measured) infiltration and recharge rates from observational studies. For subsurface analyses, primary data included: (6) aquifer thickness, (7) aquifer hydraulic conductivity, (8) confining layer thickness, (9) aquifer storativity, (10) vadose zone thickness, and (11) historical changes in water tableu elevation.

Lithologic descriptions were used to classify geologic units in terms of whether or not they corresponded to aquifers, or if fine-grained sediment (clay and silt) would be likely to reduce direct connection to underlying 
aquifers. Higher MAR suitability is associated with outcropping aquifers units. The infiltration capacity of basin soils was mapped in irregular polygons. Land use classifications included native vegetation, urban, and agricultural areas designated by crop type and/or agriculture practice. Land surface slope values were calculated from the 10-m resolution USGS National Elevation Dataset (ned.usgs.gov). Locations of measured seepage rates were reported in earlier studies based on differential gauging, streambed geothermometry, and existing MAR projects.

Several subsurface datasets were prepared during development of the regional Pajaro Valley Hydrologic Model (PVHM) (Hanson 2003; PVWMA 2012; Hanson et al. 2014), then modified for the GIS analysis of MAR suitability. Aquifer properties, including layer thicknesses, hydraulic conductivity, and storativity, were assembled using data from more than 900 well logs distributed throughout the basin, and compiled on a grid having horizontal resolution of $250 \times 250 \mathrm{~m}$ and variable cell thickness. The unsaturated zone thickness was calculated by subtracting the interpolated water table elevations, using data collected in 2010, from the ground elevation.

Commonly, integration of GIS datasets such as these requires reclassification of data to a shared value scale and then assigning a weight to each dataset in proportion to its perceived importance. For each grid cell in the analysis, an index is calculated by summing the products of value and weight for each dataset:

$$
\operatorname{Index}(x, y)=\sum_{i=1}^{n} v_{i}(x, y) w_{i}
$$

where $n$ is the total number of datasets, $v_{i}$ is the classified value for dataset $i$ at location $(x, y)$, and $w_{i}$ is the weight assigned to dataset $i$. We defined a weighting scheme for use in this study based on (1) a review of published recharge mapping studies that used a similar GIS-based approach, (2) consideration of available datasets, and (3) inferences as to how groundwater recharge might be influenced by coexisting factors (Figure 2).

Our approach differs in several respects from methods applied in earlier GIS-based studies of natural recharge and potential for increasing recharge. Most significantly, rather than simply combining all available datasets as independent indicators through a process of weighted summation (as with Equation 1, the most common approach found in the literature), we used individual datasets as modifiers for other datasets before combining data coverages (as described in the next section). In addition, locations for which there were direct measurements of recharge rates (set 5), were assigned MAR suitability values based entirely on direct observations, which are considered to be the most reliable of available data types.

\section{Data Classification}

We standardized several of the datasets by classifying values or properties on a relative scale of 1 to 5 , where 1 represents an unfavorable attribute for MAR suitability,

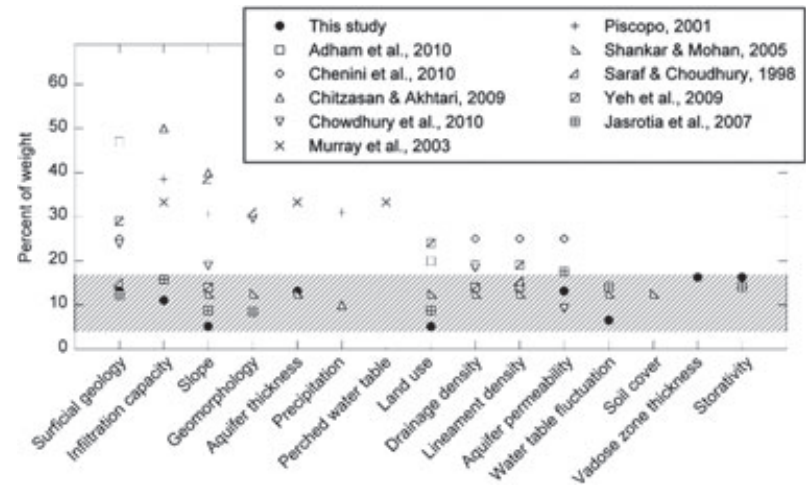

Figure 2. Comparison of dataset weights used in other studies to map groundwater recharge with a GIS. The normalized weights used in this study are shown in as solid circles, bounded by the stippled gray band. Values shown for land use and slope are calculated means of values used, because these datasets were used as modifiers for other datasets, as discussed in the text.

and 5 represents a favorable attribute. Numerical and nonnumerical datasets (e.g., soil infiltration capacity and surficial geology, respectively) required different methods for classification before data could be combined. We used three approaches for classifying numerical datasets: (1) classify values based on knowledge of field properties and past MAR operations, (2) classify values using a natural breaks method based on the distribution of property values, and (3) operate on raw data. The first method was applied to soil infiltration capacity and locations with stream seepage rates measured in the field (Table 1). The second method is based on a Fisher-Jenks algorithm (Fisher 1958; Jenks 1967), and was applied to specific yield, unsaturated zone thickness, and historical changes in water table height. The third method was applied to surface slope values. Nonnumerical datasets were classified based on interpretation of associated properties that could influence MAR. For surficial geology, we assigned each lithologic unit a value based on whether the mapped lithology and texture corresponded to a known aquifer or would likely be connected to a known aquifer. For land use, we classified descriptions based on associated roughness coefficient values (Chow 1959) (Table 1).

\section{Data Integration}

Earlier studies of recharge potential treated infiltration capacity, slope, and/or land use as independent variables (e.g., Jasrotia et al. 2007; Yeh et al. 2009). We reasoned that the primary influence of slope and land use should be to modify soil infiltration capacity $\left(I_{\mathrm{C}}\right)$, and developed an equation that incorporates dependencies on land slope $(s)$ and roughness $(n)$. This approach is similar to that used with the Manning equation for calculating mean runoff velocity in open channels, and yields an effective infiltration capacity $\left(I_{\mathrm{E}}\right)$ :

$$
I_{\mathrm{E}}=I_{\mathrm{C}}+\ln \left[\frac{n / \sqrt{s}}{(n / \sqrt{s})_{\max }}\right]
$$


Table 1

Classification of Data Based on Physical Properties

\begin{tabular}{|c|c|c|c|c|c|c|c|c|c|}
\hline \multicolumn{2}{|c|}{ Soil Infiltration Capacity } & \multicolumn{2}{|c|}{ Stream Seepage } & \multicolumn{2}{|c|}{ Aquifer Storage } & \multicolumn{2}{|c|}{ Surficial Geology } & \multicolumn{2}{|c|}{ Land Use } \\
\hline Rate $(\mathbf{m} / \mathbf{d})$ & Value & Rate $(\mathbf{m} / \mathbf{d})$ & Value $^{1}$ & $S_{\mathrm{y}} T_{\mathrm{u}}(\mathrm{m})$ & Value & $\begin{array}{l}\text { Connection } \\
\text { to Aquifer }\end{array}$ & Value & Description & $\begin{array}{l}\text { Roughness } \\
\text { Coefficient }^{2}\end{array}$ \\
\hline$>3$ & 5 & $>1$ & 80 & $64.01-131$ & 5 & Good & 5 & Forest/Nat. veg. & 100 \\
\hline 1.2 & 4 & 0.2 to 1 & 60 & $40.01-64$ & 4 & Moderate & 3 & Pasture & 40 \\
\hline 0.6 & 3 & & & $22.01-40$ & 3 & Poor & 1 & Field crop & 38 \\
\hline 0.2 & 2 & & & $8.01-22$ & 2 & & & Row crop & 35 \\
\hline \multirow[t]{3}{*}{0} & 1 & & & $0-8$ & 1 & & & Fallow & 30 \\
\hline & & & & & & & & Turf & 27 \\
\hline & & & & & & & & Pavement & 14 \\
\hline
\end{tabular}

${ }^{1}$ Stream seepage rates were determined from direct observations and assigned values that represent suitable locations for MAR. For locations where $L$ is measured, the MAR suitability index $=L$ (Equation 7).

${ }^{2}$ Roughness coefficients from Chow (1959) used in Equation 2.

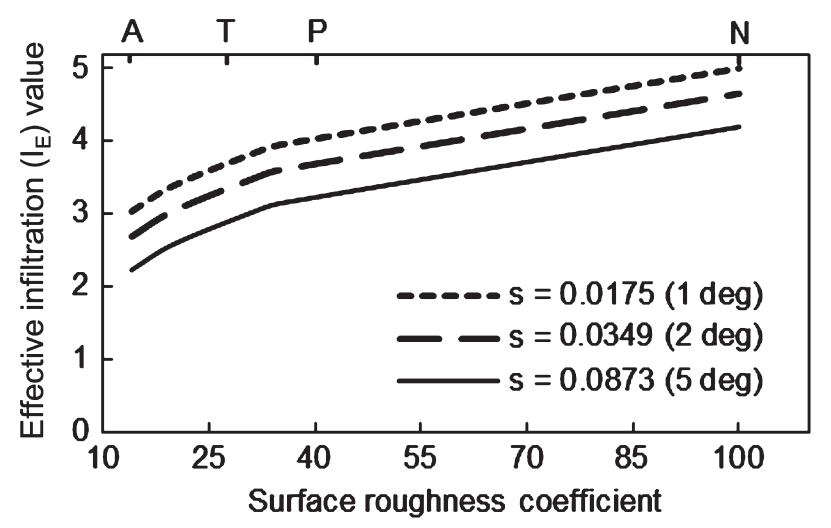

Figure 3. Example calculated effective infiltration $\left(I_{E}\right)$ values for a given infiltration capacity $\left(I_{C}\right)$ value of 5 , roughness coefficients 14 to 100, and three slope values. Roughness coefficients for pavement (A), turf/urban ( $T)$, pasture (P), and natural/forest $(\mathrm{N})$ are shown on the upper $x$-axis. The $I_{\mathrm{E}}$ curves move down for larger slopes and smaller $I_{\mathrm{C}}$ values.

where $I_{\mathrm{C}}$ is infiltration capacity based only on soil type, $n$ is a surface roughness coefficient (with values ranging from 14 to 100 , based on land use classification), and $s$ is slope in radians (extracted from the regional digital elevation model). The second term in Equation 2 accounts for water that runs off rather than infiltrating. Because the product of square-root-slope and surface roughness is normalized by the maximum (optimal) conditions for the region, the second term is less than or equal to 0 . Calculated effective infiltration values are thus dependent on the soil infiltration capacity $\left(I_{\mathrm{C}}\right)$, but modified by surface slope and roughness (extent of runoff) (Figure 3).

High transmissivity $(T)$ is important for MAR projects to avoid excessive mounding (which could waterlog the root zone of crops or contribute to flooding) and spread project benefits to nearby areas. The primary constraints on transmissivity with respect to MAR are aquifer hydraulic conductivity $(K)$ and thickness $(b)$ and the presence or absence of confining layers between the ground surface and the underlying aquifer (three separate subsurface datasets). To account for spatially variable $K$ and $b$ and the presence of confining layers, we calculate an effective transmissivity $\left(T_{E}\right)$ as it applies to MAR suitability:

$$
\begin{gathered}
T_{E}=K_{A 1} b_{A 1}+K_{C_{1}} b_{C_{1}}+F_{1}\left[K_{A_{2}} b_{A_{2}}+K_{C_{2}} b_{C_{2}}\right. \\
\left.+F_{2}\left(K_{A_{3}} b_{A_{3}}+K_{A_{4}} b_{A_{4}}\right)\right] \\
F_{1}=1-\frac{b_{C_{1}}-1}{9} \text { for } 1 \leq b_{C_{1}} \leq 10 \\
F_{2}=1-\frac{b_{C_{2}}-1}{9} \text { for } 1 \leq b_{C_{2}} \leq 10
\end{gathered}
$$

where $A_{1}$ to $A_{4}$ are aquifer units and $C_{1}$ and $C_{2}$ are confining units below $A_{1}$ and $A_{2}$, respectively. $F_{1}$ and $F_{2}$ are confining unit factors that affect the contribution of underlying aquifer units, scaled linearly between 1 and 0 for confining unit thicknesses of $1 \mathrm{~m}$ to $10 \mathrm{~m}$, respectively. Thus the transmissivities of multiple aquifer layers are combined (in part or in full) if confining layers between separate aquifer layers are less than $10 \mathrm{~m}$ in thickness. This vertical integration accounts for noncontinuity of thin confining layers. Calculated $T_{\mathrm{E}}$ values were subsequently classified on a scale of 1 to 5 per, as described in the Data Classification section.

Available storage space $(V)$ was assessed by multiplying aquifer specific yield $\left(S_{\mathrm{y}}\right)$ by the unsaturated (vadose zone) thickness $\left(T_{\mathrm{u}}\right)$ of each cell: $V=S_{\mathrm{y}} T_{\mathrm{u}}$. Unsaturated zone thickness may be relatively large below hilltops, but the complete GIS analysis includes other parameters (such as depth to confining units) that influence MAR suitability. MAR suitability was additionally enhanced in areas where there has been a large recent drop in water table elevation.

Following calculations and classifications, each dataset was assigned a weight based on the perceived importance of individual properties and conditions to positioning of potential MAR projects, in consideration 
of values used in earlier peer-reviewed studies of other basins. The normalized weights used in this study are comparable to those used in earlier studies (Figure 2), although there is considerable variability between studies depending on the number and type of available datasets and local hydrogeology. Weights shown for the infiltration capacity, slope, and land use in Figure 2 are the means of weights applied when calculating effective infiltration for the PVGB (Equation 2).

A final distribution of MAR suitability was created by summing the weighted, classified values (all varying from 1 to 5 , from least to most suitable for MAR) for every 10-by-10 $\mathrm{m}$ grid cell for which all datasets existed:

MAR suitability index $=5 I_{\mathrm{E}}+4 G+5 \mathrm{~V}+4 T_{\mathrm{E}}+2 D$

If $L$ exists, MAR suitability index $=L$

where $G$ is surficial geology, $D$ is recent change in water table height, and $L$ is the index for an area where recharge rates have been measured (other variables defined earlier). We reasoned that effective infiltration properties and the volume of storage space should be weighted most strongly at 5, with formation transmissivity and outcropping of primary aquifers weight at 4 . The recent change in water level was given the least weight because of the uncertainty associated with interpolating from limited measurements. The full process was automated using scripts, allowing future modification and rapid updating of map products as additional datasets become available, field data are collected to test predictions, or weighting methods are changed based on availability of new information.

\section{Numerical Modeling of MAR Scenarios}

To model the relative hydrologic impact of hypothetical MAR projects, and the importance of project placement and operational parameters, we use a regional hydrogeologic model developed for the study area (PVWMA 2012; Hanson et al. 2014). The details of model development, and of creating and applying a regional model for assessing historical groundwater extraction and conditions, are presented elsewhere (Hanson 2003; PVWMA 2012, 2013; Hanson et al. 2014), and summarized briefly herein. Surface and subsurface hydrologic processes were simulated using MODFLOW-2005 (Harbaugh 2005) in conjunction with the Farm Process Package (Schmid and Hanson 2009; Hanson et al. 2010). The model domain extends from the back of the basin (bounded by the San Andreas Fault) to more than $10 \mathrm{~km}$ offshore (Figure 4A), with grid resolution of $250 \times 250 \mathrm{~m}$. The model has six layers that vary in thickness across the basin, corresponding to aquifer and confining layers (Figure 4B). The model has no-flow boundaries at the base and on the southeastern and eastern lateral sides, corresponding to the low-permeability foothills and the San Andreas Fault. General head boundaries (GHB) were used on the northern and southern lateral sides and
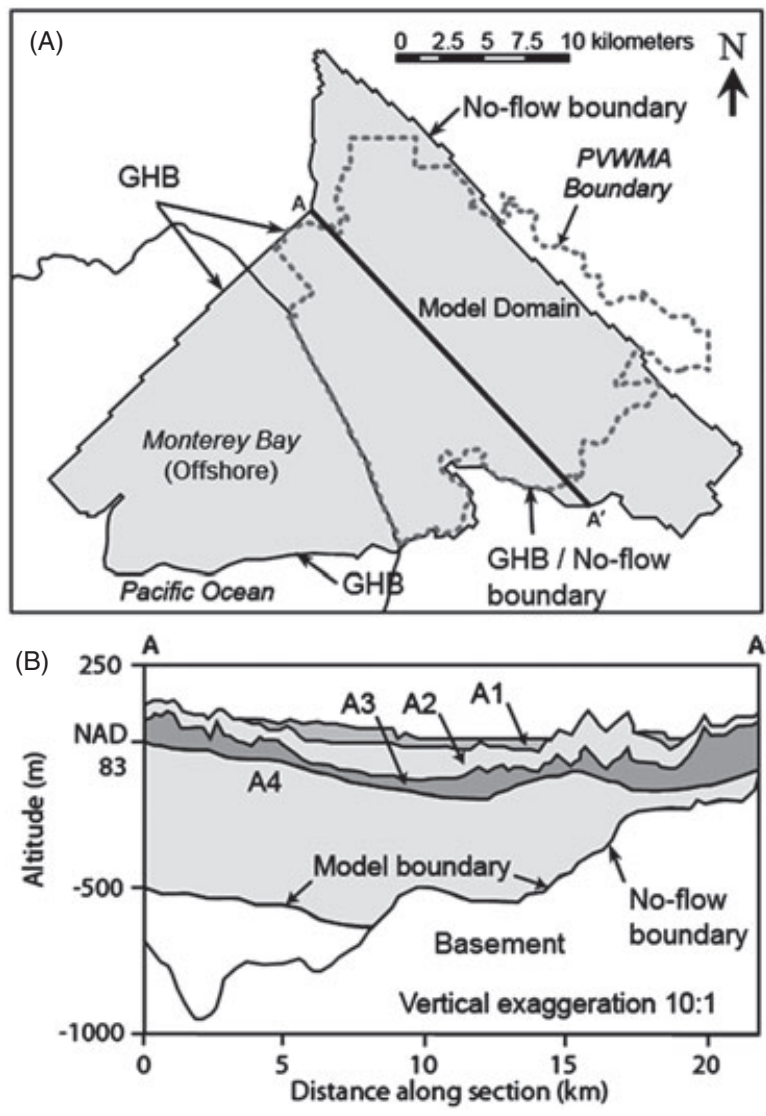

Figure 4. Pajaro Valley Hydrologic Model (PVHM), (A) map view of model domain (gray), (B) illustrated cross section showing model layers along transect A-A'. Modified from Hanson et al. (2014).

offshore. The SE side has no-flow boundaries for the alluvium (Layer A1), and GHBs for the lower layers, see Hanson et al. (2014) for details. Median monthly sea level changes were used to calculate offshore head boundaries, based on regional sea level rise projections for the time period modeled (PVWMA 2012). The model includes nearly 1000 active production (agricultural, municipal, domestic) groundwater wells. The Farm Process modifies agricultural groundwater pumping rates during simulation based on changes in land-use, climate, and groundwater availability (Hanson et al. 2010). The simulations used in this study represent 34 years (nominally conditions from 1976 to 2009) divided into 408 (monthly) stress periods, each having two time steps.

We worked with a Basecase simulation developed to represent a 34-year time period beginning nominally in 2009 (PVWMA 2012; Hanson et al. 2014). Climate conditions for the Basecase simulation were assigned to be those of the preceding 34 years, but reversed in sequence, and land use in the simulations was fixed to be that from 2009. Sea level increased over time to follow regional projections (PVWMA 2012). The same climate conditions and land use patterns were used in the Basecase and MAR scenarios. This approach allowed us to assess the influence of MAR operating scenarios in the context of a historically realistic range of conditions, but is not intended to 
comprise a prediction of future climate, water or land use, or pumping patterns. After the Basecase simulation was completed, we ran additional simulations of hypothetical MAR project scenarios, adding water in different locations and at different rates around the basin. Differences in simulated groundwater levels and the extent of sea water intrusion, as compared to results from the Basecase model, are interpreted to assess potential MAR "benefit."

MAR projects were simulated by adding water to the surface aquifer layer using a specified flux boundary condition (equivalent to an injection well in the surface layer). It was assumed that each MAR project existed within a single model cell (6.3 hectares, 15.6 acres). Adding water directly to the top cell layer did not allow evaluation of how surface properties (slope, land use, and soil infiltration capacity) influenced recharge dynamics, but subsurface storativity, transmissivity and the presence of confining units governed flow after infiltration. Evapotranspirtation was modeled regionally as part of the Farm Process, but an earlier study of MAR in the study area showed that evaporation occurred at a rate less than $1 \%$ of water infiltration during MAR (Racz et al. 2011), so this process was neglected in this study.

Modeled MAR scenarios included four variables: (1) project locations, (2) number of projects, (3) quantity of applied water per project (and in total), and (4) duration of activity during each year. We evaluated the influence of locating MAR projects based on results of the MAR suitability analysis and geographical considerations. Two sets of models were run based on placing MAR projects randomly across areas identified with the GIS analyses as having high MAR suitability ("MS-High") or low suitability ("MS-Low"). Two additional sets of models were run based on placing MAR projects in areas of high suitability that are either near the coast ("Coastal") or along the back (eastern side) of the basin ("Back-basin"). MAR sites in each location deliver recharge to different model layers, depending on which aquifer is exposed or closest to the surface.

Each modeling scenario had either 5 or 10 MAR projects. The rate of MAR-associated recharge applied at individual project sites ranged from $6.2 \times 10^{4} \mathrm{~m}^{3} / \mathrm{yr}$ $(50 \mathrm{ac}-\mathrm{ft} / \mathrm{yr})$ to $1.5 \times 10^{6} \mathrm{~m}^{3} / \mathrm{yr} \quad(1200 \mathrm{ac}-\mathrm{ft} / \mathrm{yr})$, comparable to the amount of water that might be applied based on stormwater capture of runoff (near the lower end) or diversion from major aquatic systems (near the higher end). Water was applied evenly during periods of either 4 or 12 months/year. The 4-month MAR scenario was intended to represent projects operated only during the wet season, whereas the 12-month MAR scenario represents water delivered from a recycling plant or another non-seasonal source.

To analyze MAR scenario results, we compared the PVHM output of head levels and flows from the ocean into the coastal aquifers. Changes in head levels were quantified for a given time over the entire basin in Layer A2 (the most developed aquifer layer in the region, Figure 4B) during the final time-step compared to head levels from the end of the Basecase simulation. The flow of water inland from offshore was evaluated as a proxy
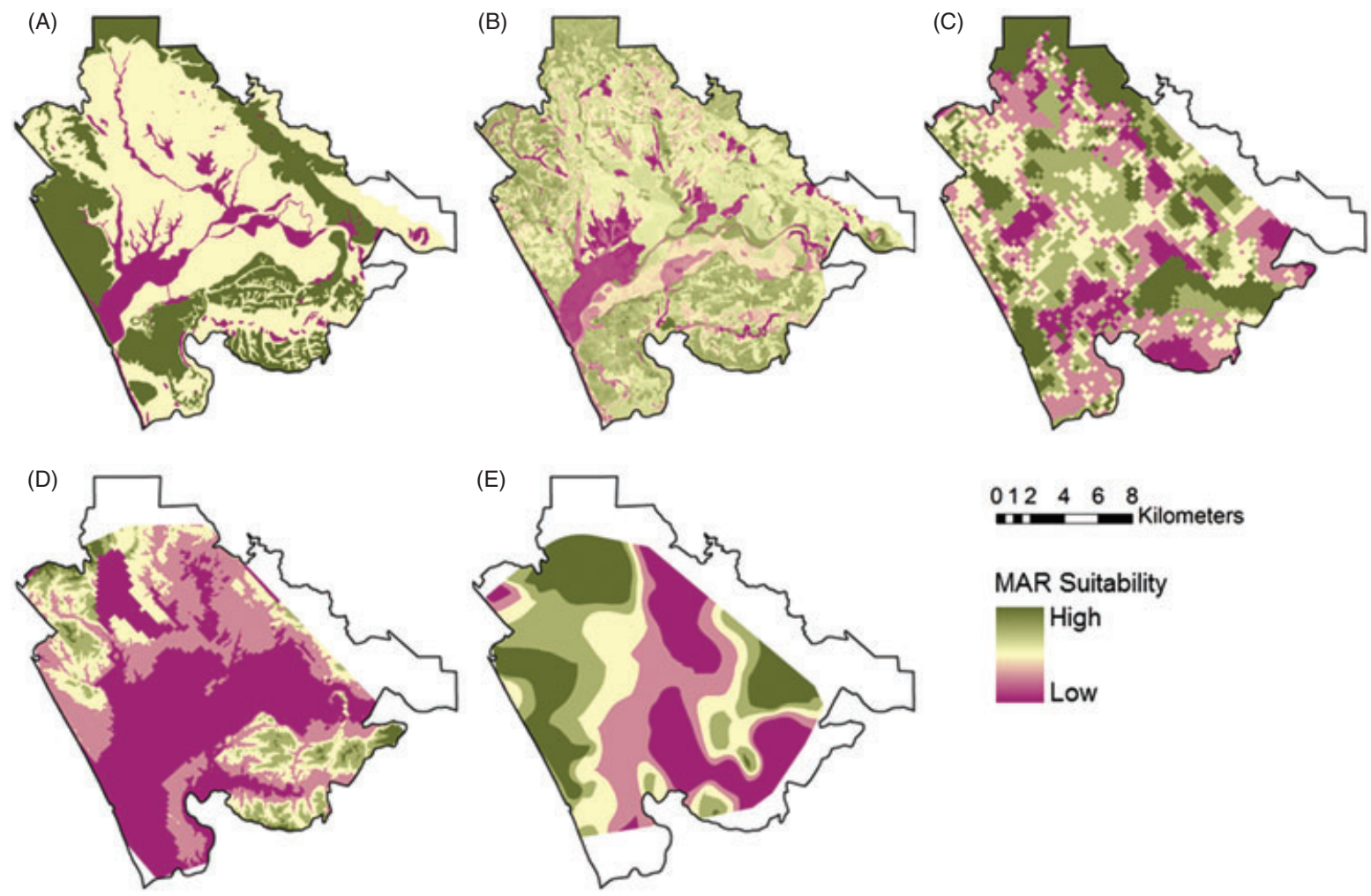

MAR Suitability

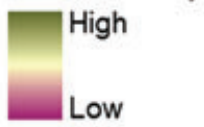

Figure 5. Classified surface and subsurface properties used to determine relative MAR suitability. (A) Surficial geology, (B) effective infiltration, (C) effective transmissivity, (D) storage availability, (E) change in groundwater elevation (2010-1998). 
for sea water intrusion. Modeled coastal flows were calculated for each stress period, then summed to generate rates of flow per year over the duration of the model run. Flux values are interpreted to represent either sea water intrusion (flow inland from the ocean) or groundwater losses (flow from aquifer layers to the ocean).

\section{Results}

\section{Distribution of Classified Properties and MAR Suitability for the PVGB}

Results from classification of surface and subsurface properties are shown in Figure 5. The majority of the surficial geology in the PVGB indicates neutral to favorable connectivity to shallow local aquifers, except on the floodplain of the Pajaro River system (particularly within and adjacent to the Watsonville Sloughs), where there are significant shallow silt and clay layers (Figure 5A). Effective infiltration $\left(I_{\mathrm{E}}\right)$ (Figure 3 ) is suitable for MAR across much of the PVGB, except in urban areas, below nurseries, and on the floodplain of the Pajaro River (Figure 5B). Classified values of effective transmissivity $\left(T_{\mathrm{E}}\right)$ are heterogeneous across the basin, and show little correlation with surface properties (Figure 5C). Available storage $(V)$ is low for much of the central valley and coastal region, with higher values in the northwest and southeast areas that have higher elevations (Figure 5D). Groundwater levels have generally been lowered the most near the coast and along the most northern and western parts of the basin, relative to water levels in 1998, but there is a band of higher groundwater levels that runs north-south through the center and to the southwestern side of the basin (Figure 5E).

The spatial datasets were combined to generate a distribution of MAR suitability across the PVGB, with a nominal resolution of $10 \times 10 \mathrm{~m}$ (Figure 6). Calculated MAR suitability index values range from 6 to 97 (low to high suitability) and follow a roughly normal distribution, with a mean of 52 and a standard deviation of 14 . The upper quartile of this range, comprising land areas being the most suitable for MAR, accounts for $7 \%$ of the analyzed land area in the PVGB $\left(15 \mathrm{~km}^{2}\right)$. These areas are located throughout the basin, but are particularly concentrated along the coast north and south of the Pajaro River, inland south of the Pajaro River, and along the eastern side (back) of the basin (Figure 6). The site of an existing MAR project, that uses water diverted from a slough during high flow conditions (Racz et al. 2011; Schmidt et al. 2011a), has a MAR suitability index of 78 , in the 96th percentile of areas evaluated (Figure 6).

\section{Modeling the Influence of Distributed MAR Project Options on Resource Conditions}

Models of MAR scenarios (Figure 7) illustrate how simulated projects influence aquifer conditions and flows relative to the Basecase model. Unsurprisingly, groundwater levels increased the most in locations closest to and within the aquifer layer directly recharged by MAR

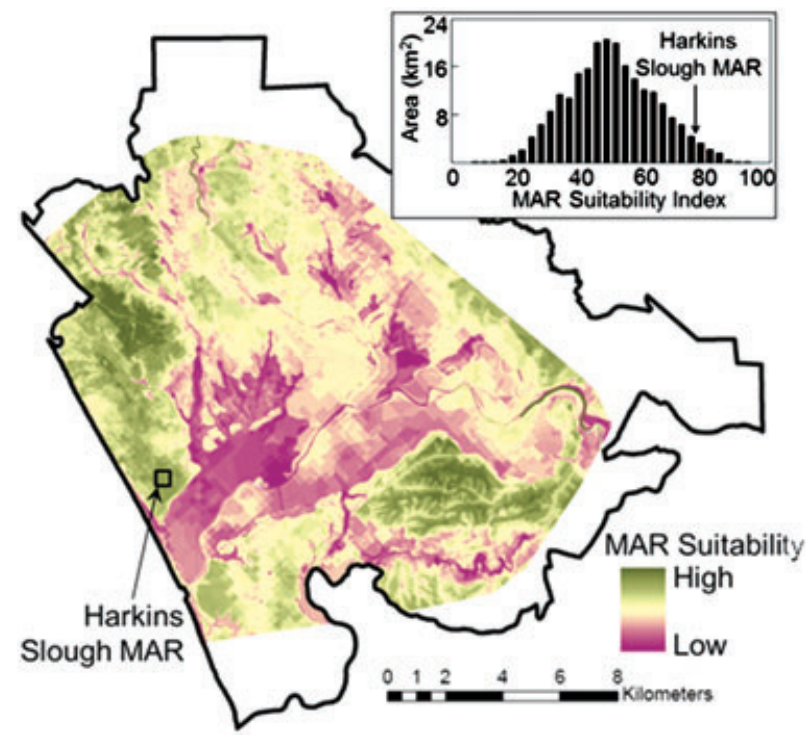

Figure 6. Map of relative MAR suitability determined by GIS-based integration. The location of an existing MAR project (Harkins Slough) is indicated with a square. (Inset) The area distribution of MAR suitability index values, with the index of the Harkins Slough project noted (78).

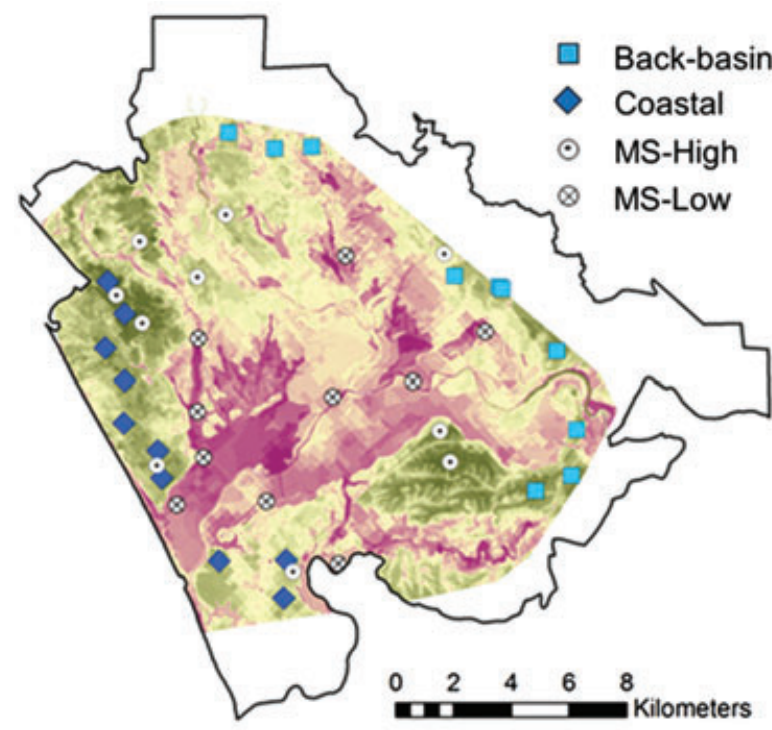

Figure 7. MAR scenario location groups shown on the MAR suitability index map. Ten site locations are shown for each of the four groups: Coastal, Back-basin, MS-High, and MSLow.

(e.g., Figure 8). Project placement in highly suitable areas results in the greatest increase in water levels in the northwest part of the PVGB, and produces more than $1 \mathrm{~m}$ head level increase in more than $80 \%$ of the onshore area (Figure 8A). Project placement close to the coast raises head levels the most in these areas, on the western side of the PVGB, and produces a more than $1 \mathrm{~m}$ head level increase across approximately $60 \%$ of the onshore area (Figure 8B). 

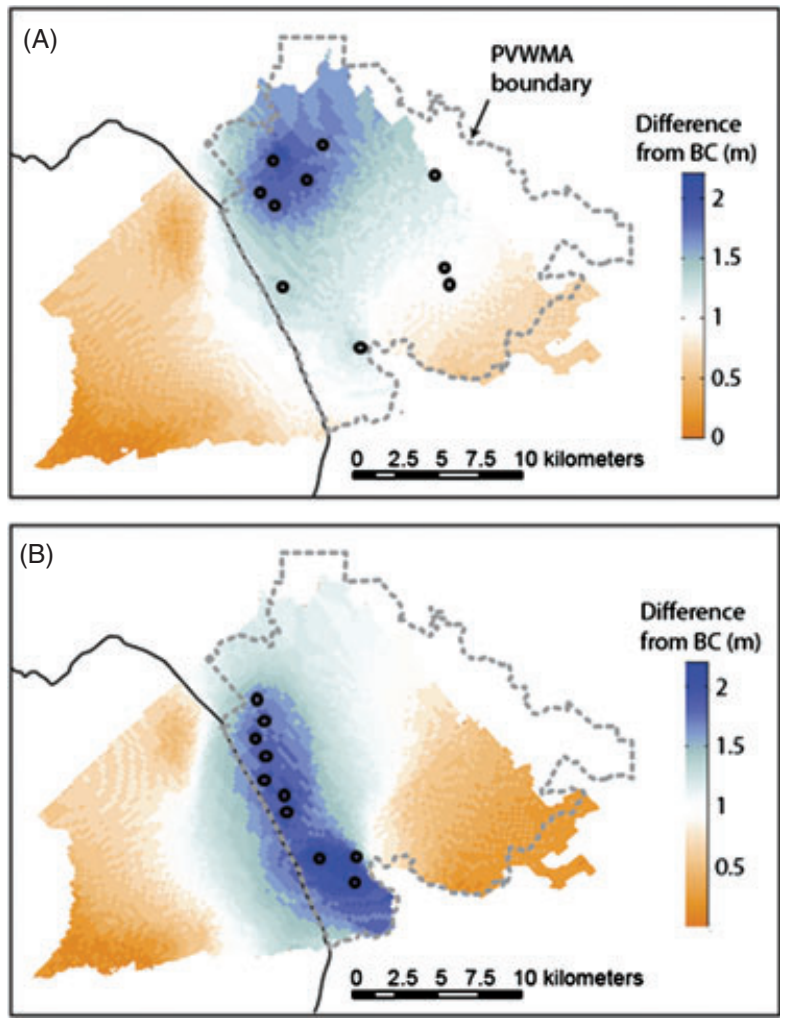

Figure 8. (A) Increase in head levels in Layer A2 at model year 34 due to MAR projects in MS-High locations relative to the Basecase. (B) Similar results MAR projects placed in Coastal locations. Both scenarios have 10 MAR projects (black circles) applying $4.6 \times 10^{5} \mathrm{~m}^{3} / \mathrm{yr}$ (400 ac-ft/yr).

For all tested scenarios, simulated MAR projects reduced sea water intrusion compared to the Basecase, with the benefit increasing over time (Figure 9). There is a period of significant reduction in the extent of sea water intrusion, between simulation years 21 and 27, coinciding with a dry period which increased sea water intrusion in the Basecase relative to the MAR scenarios. Although the timing and magnitude of similar climatologic events, and associated changes in pumping patterns, are difficult to predict, this variability illustrates a common practical challenge in assessing the impacts of MAR and other practices intended to improve sustainability, and the need for taking a long view in assessing benefits.

The location of modeled MAR projects has a notable influence on the magnitude of long-term reductions in sea water intrusion. The greatest simulated benefit is achieved when MAR projects are placed across the basin in locations identified as highly suitable for MAR. The next greatest reduction in sea water intrusion is achieved with placement near the back of the basin, and placement of all MAR projects along the coast has the smallest long-term reduction in sea water intrusion, although it generates more short-term benefit (Figure 9). Placement in highly suitable locations across the basin provides about twice the long-term intrusion reduction when compared to project placement along the coast. All models based on creating new MAR projects increase

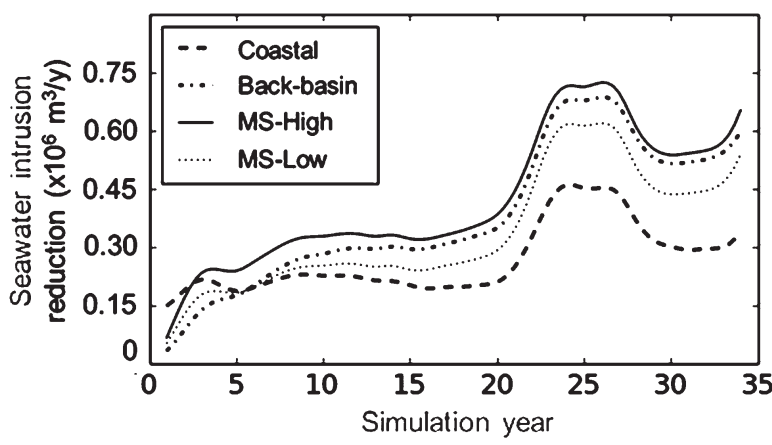

Figure 9. Reduction of sea water intrusion relative to the Basecase due to MAR projects simulated in four regions of the basin, respectively, shown versus time. Each scenario has five MAR projects, each applying $9.8 \times 10^{5} \mathrm{~m}^{3} / \mathrm{yr}$ and operating 12-mo/yr.
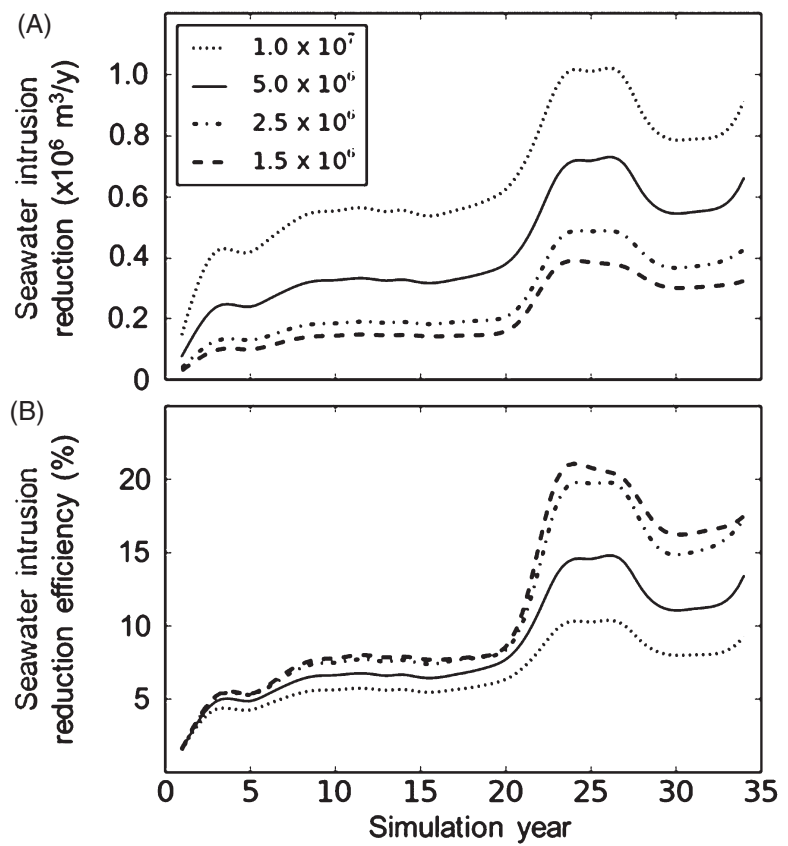

Figure 10. Simulation results with varying rates of total applied water $\left(\mathrm{m}^{3} / \mathrm{yr}\right)$ at MS-High sites, operating $12-\mathrm{mo} / \mathrm{yr}$. (A) Sea water intrusion reduction relative to the Basecase and $(B)$ intrusion reduction efficiency.

groundwater flows to the ocean, but this increase tends to be highest in the first 5 to 15 years and subsequently decreases as lateral head gradients are reduced and/or more water is extracted from the basin by pumping. The Coastal scenario results in the greatest increase in flow of groundwater to the ocean compared to the Basecase.

As anticipated, there is greater reduction in sea water intrusion when more water is recharged (Figure 10A), but there are differences in efficiency (calculated as reduction in sea water intrusion divided by water applied per year) (Figure 10B). After the first year of simulation, the efficiency is relatively low, on the order of $1 \%$ to $2 \%$, and it takes several years until larger benefits from MAR are accrued. MAR efficiency increases over the long term 
for all scenarios, but there is a greater rate of efficiency increase for lower rates of applied water. Larger rates of applied MAR water result in disproportionate increases in groundwater flows to the ocean (offshore flow).

Changing the number of MAR projects from 5 to 10 generally has the same influence as doubling the total applied water at the same number of sites. In practice, locations selected for installation of additional MAR projects will influence local results because of differences in properties, pumping rates, and other factors. Scenarios based on 4 month and 12 month operations (with same total applied water) have nearly identical influence on sea water intrusion for the first 20 years of the model simulation, after which projects with 12 month operation tend to have approximately $5 \%$ to $8 \%$ greater impact than do the projects operating only 4 months per year.

\section{Discussion}

\section{Classification and Merging of GIS Datasets}

Most peer-reviewed, GIS-based studies completed to assess recharge properties and processes have focused on natural or incidental recharge, rather than MAR (Figure 2). Each of these studies used a different weighting system for combining disparate datasets, and few earlier studies attempted to test the results of GIS-based analyses for accuracy or applicability. We attempted to address this latter issue, in part, by linking the GIS analysis to deterministic modeling, although this approach cannot confirm the "correctness" of regional interpretations.

One approach for development of a suitable weighting system for applying GIS data is to generate a suitability map that follows a desired distribution (e.g., normal, log-normal). If the fundamental goal is to distinguish between the relative suitability of candidate field sites within a basin, this approach will delineate land areas having characteristics of a desired percentile of analyses (top 10\%, best 100 hectares, etc.). GIS analyses are probably best applied to guide or inform (rather than dictate) MAR placement as a component of critical water resource decisions.

Our data integration approach differed from those taken in earlier studies in that we combined multiple datasets to generate interim interpretations of effective properties. Effective infiltration capacity encompasses the relationship between traditional soil infiltration capacity, ground slope, and surface roughness. We reason that a greater slope and smoother land surface should serve mainly to reduce the relative rate of infiltration, given intrinsic soil properties. Slope and roughness should have less influence for soils that have a low infiltration capacity, but these factors could result in a larger reduction in infiltration through highly permeable soils. Similarly, we calculated effective transmissivity values for a series of aquifer layers, by summing all (or part of) the values of individual layers from the surface downwards until a significant confining unit was encountered. The traditional approach for calculating equivalent vertical hydraulic conductivity and subsequently transmissivity could either under-represent effective values of areas where there are multiple (partly confined) aquifer units, but only the shallowest is assessed, or over-estimate transmissivity if the presence of shallow confining layers were ignored.

\section{Integration of GIS Analyses and Numerical Modeling}

This study links a GIS-based assessment of MAR suitability to the calculated influence of MAR projects using a numerical model. Several of the surface and subsurface datasets used for the GIS analysis were created originally as part of the model development, which began before the GIS work. Linking GIS and modeling studies helped to assure that data and assumptions were consistently applied across these two sets of methods. Modification of the PVHM to include MAR projects facilitated evaluation of the relative influence of major MAR characteristics, including project location, number of projects, amount of water applied, and duration of operation through the year. Resource managers and stakeholders in many groundwater basins have access to similar datasets, although their resolution, accuracy, and completeness vary considerably. The availability of a geologically detailed and up-to-date regional groundwater model that can be run on the basis of a GIS-based analysis of MAR is more unusual and may be a key limiting factor in many basins.

\section{Implications for MAR in the Pajaro Valley}

Our GIS-based analyses using 11 regional datasets show considerable variability of MAR suitability (Figure 6). The most prominent feature in the final MAR suitability map is the Pajaro River floodplain and associated wetland areas, which have relatively low MAR suitability primarily due to soil infiltration and surficial geology classifications. The GIS analysis might normally result in assigning similarly poor infiltration properties to the bed of the Pajaro River, because regional soil surveys are often not extended into active river channels, but differential gauging and seepage studies documented streambed losses on the order of $1 \mathrm{~m} / \mathrm{d}$ along the eastern part of the river near the back of the basin (Ruehl et al. 2006; Hatch et al. 2010). This discrepancy illustrates a limitation of the GIS-based approach: most regional datasets and models do not fully capture local heterogeneities in material properties.

Our GIS analyses suggest that an existing MAR facility in the PVGB (Racz et al. 2011; Schmidt et al. 2011a) is located where the calculated MAR suitability index is 78 , an index value met or exceeded by only $4 \%$ of the basin $\left(8.7 \mathrm{~km}^{2}\right)$. MAR suitability values within the upper quartile of the calculated range were found for $7 \%\left(15 \mathrm{~km}^{2}, 3.8 \times 10^{3}\right.$ acres$)$ of the PVGB, suggesting that there may be numerous locations worth considering as potential project sites. Fifteen individual projects generating $10^{6} \mathrm{~m}^{3} / \mathrm{yr}(800 \mathrm{ac}-\mathrm{ft} / \mathrm{yr})$ of additional recharge would be needed to offset annual overdraft in the PVGB (PVWMA 2012), requiring less than 5\% of land that has MAR suitability equal to or greater than that of the existing MAR project site. Of course, this assessment does 
not account for water supply availability, likely changes to land use and climate, or differences in MAR benefit efficiency associated with geographic placement.

\section{Influence of MAR Location, Water Applied, and Years of Operation}

Model results showed that MAR project location, amount of applied water, and years of operation affect groundwater conditions in different ways. Projects located close to the coast provide the greatest immediate benefit through reduction of sea water intrusion, but after a few years, sea water intrusion reduction is greatest for scenarios that place MAR projects throughout the PVGB or in the back (East side) of the basin. This results in part from the hydrogeology of the areas where the projects are simulated. For example, sites along the coast overlie a ubiquitous confining unit $(\mathrm{C} 1)$ that separates the surface aquifer from A2 and A3. MAR projects located in the MS-High and Back-basin sites have a better likelihood of recharging layers $\mathrm{A} 2$ and $\mathrm{A} 3$, which are heavily pumped. Also, as the total quantity of water recharged increases over time, project efficiency decreases due to groundwater flows to the ocean. These offshore flows would likely help to slow degradation of (or could lead to improvement in) groundwater quality, not assessed in this study, but they don't correspond directly to an increase in stored fresh water.

Modeling results illustrate how the benefits from MAR projects vary depending on which evaluation metric is used (groundwater rise vs. sea water intrusion reduction), and where the metrics are applied in the basin. MAR projects located at coastal sites result in the largest groundwater head increase along the coast (Figure 8), but also the lowest long-term reduction in sea water intrusion (Figure 9). Projects located in group MS-High are most effective at reducing sea water intrusion, even when most of these are located relatively far from the coast. This illustrates the importance of assessing both surface and subsurface properties and conditions when comparing locations for MAR projects, and for consideration of longterm impacts rather than only the most immediate benefits.

\section{Study Limitations}

Factors not accounted for in the GIS analyses include water availability, water quality, unsaturated zone transport, site access, land use, and proximity to areas that are already intruded by sea water. These factors should be considered as part of project scoping and pilot testing, and for evaluating basin management scenarios more broadly. The GIS analyses were not intended to be the primary basis for making placement and operational decisions for MAR project sites. They were intended to help assess relative impacts of MAR scenarios, and thus are best applied as screening and guidance tools to focus site studies.

This study does not assess water availability for MAR projects. Additional work is needed to merge an evaluation of MAR suitability with an analysis of precipitation distribution, runoff, streamflow, and other surface water availability. Assessment of runoff will require land parcel owner information, and quantification of runoff accumulation should include analyses of potential benefits from earthwork site by site. Assessment of surface water availability, including stream diversions and recycled water supply, will require consideration of political, economic, and ecological factors.

The model does not include solute sources or advection, and therefore cannot estimate the influence of recharge on water quality. Future improvements to this method could include adding solute transport capabilities. For example, placing MAR projects within the sea water intruded area might be a feasible option for reducing the rate of future intrusion, but might not have a strong enough influence on water quality benefit to allow extraction from areas that are already intruded. Conversely, recharging onto and recovering directly from a perched aquifer above the sea water intruded area may provide an alternate source, allowing coastal water pumping to continue and reducing demand on deeper, overdrafted aquifers (Racz et al. 2011; Schmidt et al. 2011a). Recharging to a perched aquifer was not evaluated in this study.

The groundwater model uses the Farm Process (Schmid and Hanson 2009), which automatically varies the amount of water pumped based on land use, climate, and water availability. As a result, there is an eight-year increase in sea water intrusion starting in model year 21 in the Basecase, largely in response to a modeled dry period. The MAR scenario simulations also experience this increase, however to a lesser degree resulting in a net greater reduction in sea water intrusion (Figures 9 and 10). Uncertainty in climate projections and land use patterns will propagate uncertainties in predictions of future sea water intrusion rates.

\section{Conclusions}

We presented a series of methods for integrating spatial surface and subsurface data using a GIS to identify locations that may be suitable for MAR projects, and quantified the potential impacts of such projects using a hydrogeologic model. Due to uncertainties associated with future climate and pumping rates, it may be best to consider model results mainly to assess the relative benefits from MAR scenarios, rather than as quantitative predictions for planning purposes. We developed methods that allow data to be combined using traditional approaches (overlying coverages and adding indices) and by allowing some data to operate on other data before coverages are combined. We suggest that this approach has broad applicability (with adjustments to specific tools and the sequence of data merging based on basin-specific conditions) and can provide a quantitative understanding of relationships between geology, hydrology, and managed recharge. The linking of GIS and modeling studies is particularly helpful in assuring that data used are self-consistent, and that results from each can feed into the other, allowing one or both to be updated over time, and maximizing the benefit 
of compiling and processing large spatial and temporal datasets.

With respect to the example basin described in this study, our results suggest that $7 \%\left(15 \mathrm{~km}^{2}, 3.8 \times 10^{3}\right.$ acres) of the PVGB may be highly suitable for MAR projects (in the upper quartile of the quantitative range). Hydrogeologic modeling suggests that projects placed in highly suitable locations (based on GIS analyses) could reduce sea water intrusion to a greater extent than would projects located in relatively unsuitable areas. Modeling also suggests that reducing sea water intrusion might be most efficient over the long term with MAR projects distributed throughout the PVGB in highly suitable locations, rather than emphasizing sites along the coast, although coastal sites could produce more benefit over the short term.

The next steps in determining where MAR projects might be implemented are to conduct field tests of soil infiltration properties at selected field locations, assess land use and access, and evaluate potential water supplies. Ongoing activities to assess the suitability of specific areas for MAR in the PVGB include multiday infiltration tests and pilot scale MAR development. Data from future additional MAR projects will be helpful in calibrating both the GIS analyses and the regional hydrogeologic model, in addition to improving water resource conditions.

\section{Acknowledgments}

We thank Mike Cloud, Michael Cahn, and Marc Los Huertos for their thoughtful advice on land use and Pajaro Valley geology and hydrogeology. Randy Hanson provided guidance on use of the regional hydrogeologic model. This work was supported by the National Science Foundation Graduate Research Fellowship Program (ID\# 2009083666), the National Institute for Water Resources (Grants 08HQGR0054 and 2013CA307B), and The Recharge Initiative (rechargeinitiative.org). This manuscript benefited from comments by three anonymous reviewers and the editor.

\section{References}

Abarca, E., E. Vázquez-Suñé, J. Carrera, B. Capino, D. Gámez, and F. Batlle. 2006. Optimal design of measures to correct seawater intrusion. Water Resources Research 42, no. 9: 1-14. DOI: 10.1029/2005WR004524. http://www.agu. org/pubs/crossref/2006/2005WR004524.shtml.

Adham, M.I., C.S. Jahan, Q.H. Mazumder, M.M.A. Hossain, and A.-M. Haque. 2010. Study on groundwater recharge potentiality of Barind tract, Rajshahi District, Bangladesh using GIS and remote sensing technique. Journal of the Geological Society of India 75, no. 1: 432-438. http://www.springerlink.com/index/b65t762v0411706x.pdf.

Bouwer, H. 2002. Artificial recharge of groundwater: Hydrogeology and engineering. Hydrogeology Journal 10: 121-142. DOI: 10.1007/s10040-001-0182-4. http://www. springerlink.com/index/U0R3XTXNNFQM4P6Y.pdf.

Cey, B.D., B.G. Hudson, J.E. Moran, and B.R. Scanlon. 2008. Impact of artificial recharge on dissolved noble gases in groundwater in California. Environmental Science \& Technology 42, no. 4: 1017-1023.
Chenini, I., and A.B. Mammou. 2010. Groundwater recharge study in arid region: An approach using GIS techniques and numerical modeling. Computers and Geosciences 36, no. 6: 801-817. DOI:10.1016/j.cageo.2009.06.014.

Chenini, I., A.B. Mammou, and M. El May. 2010. Groundwater recharge zone mapping using GIS-based multi-criteria analysis: A case study in Central Tunisia (Maknassy Basin). Water Resources Management 24: 921-939. DOI: 10.1007/s11269-009-9479-1. http://www.springer link.com/index/53650545R6287136.pdf.

Chitsazan, M., and Y. Akhtari. 2009. A GIS-based DRASTIC model for assessing aquifer vulnerability in Kherran Plain, Khuzestan, Iran. Water Resources Management 23: 1137-1155. DOI: 10.1007/s11269-008-9319-8. http:// www.springerlink.com/index/V1387T482H53505L.pdf.

Chow, V.T. 1959. Open-Channel Hydraulics. New York: McGraw-Hill.

Chowdhury, A., M.K. Jha, and V.M. Chowdary. 2010. Delineation of groundwater recharge zones and identification of artificial recharge sites in West Medinipur District, West Bengal, using RS, GIS and MCDM techniques. Environmental Earth Sciences 59: 1209-1222. DOI: $\quad 10.1007 / \mathrm{s} 12665-009-0110-9 . \quad$ http://www.springer link.com/index/e23r650210553874.pdf.

Dillon, P., P. Pavelic, D. Page, H. Beringen, and J. Ward. 2009. Managed aquifer recharge: An introduction. Waterlines Report Series No. 13. Canberra, Australia: Australian National Water Commission.

Fisher, W. 1958. On grouping for maximum homogeneity. American Statistical Association Journal December: 789-798.

Fryar, A.E., S.A. Macko, W.F. Mullican III, K.D. Romanak, and P.C. Bennett. 2000. Nitrate reduction during groundwater recharge, Southern High Plains, Texas. Journal of Contaminant Hydrology 40, no. 4: 335-363. DOI: 10. 1016/S0169-7722(99)00059-5. http://linkinghub.elsevier. com/retrieve/pii/S0169772299000595.

Hanson, R.T. 2003. Geohydrologic Framework of Recharge and Seawater Intrusion in the Pajaro Valley, Santa Cruz and Monterey Counties, California. Sacramento, California: US Geological Survey.

Hanson, R.T., W. Schmid, C.C. Faunt, J. Lear, B.S. Lockwood, and S. Predmore. 2014. Hydrologic model of Pajaro Valley, Santa Cruz and Monterey Counties, California, scientific research investigation. Sacramento, California: US Geological Survey (in Review).

Hanson, R.T., W. Schmid, C.C. Faunt, and B. Lockwood. 2010. Simulation and analysis of conjunctive use with MODFLOW's farm process. Ground Water 58, no. 5: 674-689.

Hanson, R.T., W. Schmid, J. Lear, and C.C. Faunt. 2008. Simulation of an aquifer-storage-and-recovery (ASR) system using the farm process in MODFLOW for the Pajaro Valley, Monterey Bay, California. In Proceedings Modflow and More - Ground Water and Public Policy, 501-505. Golden, Colorado.

Harbaugh, A.W. 2005. MODFLOW-2005, the U.S. Geological Survey modular ground-water model-The ground-water flow process. U.S. Geological Survey Techniques and Methods 6-A16. Reston, Virginia: USGS.

Hatch, C., A. Fisher, C. Ruehl, and G. Stemler. 2010. Spatial and temporal variations in streambed hydraulic conductivity quantified with time-series thermal methods. Journal of Hydrology 389, no. 3-4: 276-288.

Jasrotia, A.S., R. Kumar, and A.K. Saraf. 2007. Delineation of groundwater recharge sites using integrated remote sensing and GIS in Jammu District, India. International Journal of Remote Sensing 28, no. 22: 5019-5036. DOI:10.1080/01431160701264276.

Jenks, G. 1967. The data model concept in statistical mapping. International Yearbook of Cartography 7: 186-190. 
Jha, M.K., A. Chowdhury, V.M. Chowdary, and S. Peiffer. 2007. Groundwater management and development by integrated remote sensing and geographic information systems: Prospects and constraints. Water Resources Management 21: 427-467. DOI: 10.1007/s11269-006-9024-4. http:// www.springerlink.com/index/1J153JM60180L03J.pdf.

Ma, L., and R.F. Spalding. 1997. Effects of artificial recharge on ground water quality and aquifer storage recovery. Journal of the American Water Resources Association 33, no. 3: $561-572$.

Maliva, R., and T. Missimer. 2012. Managed aquifer recharge. In Arid Lands Water Evaluation and Management, Environmental Science and Engineering, 559-630. Heidelberg: Springer-Verlag. DOI:10.1007/978-3-642-29104-3_23.

Munevar, A., and M.A. Marino. 1999. Modeling analysis of ground water recharge potential on alluvial fans using limited data. Ground Water 37, no. 5: 649-659. DOI:10.1111/ j.1745-6584.1999.tb01156.x.

Murray, J., and P.A. Mcdaniel. 2003. Development of a GIS database for ground-water recharge assessment of the Palouse Basin. Soil Science 168, no. 11: 759-768. DOI:10.1097/01.ss.0000100474.96182.5f.

O'Leary, D.R., J.A. Izbicki, J.E. Moran, T. Meeth, B. Nakagawa, L. Metzger, C. Bonds, and M.J. Singleton. 2012. Movement of water infiltrated from a recharge basin to wells. Ground Water 50, no. 2: 242-255. DOI: 10.1111/ j.1745-6584.2011.00838.x. http://www.ncbi.nlm.nih.gov/ pubmed/21740423.

Piscopo, G. 2001. Groundwater vulnerability map explanatory notes: Castlereagh catchment. Parramatta, Australia: NSW Department of Land and Water Conservation.

PVWMA. 2013. 2013, 2012 Basin Management Plan Update, Draft: January 2013. Watsonville, California: Pajaro Valley Water Management Agency/Corollo Engineers.

PVWMA. 2012. Hydrologic Model Analysis of Basin Management Plan Alternatives. Watsonville, California: HydroMetrics Water Resources, Inc., Pajaro Valley Water Management Agency.

Racz, A.J., A.T. Fisher, C.M. Schmidt, B.S. Lockwood, and M. Los Huertos. 2011. Spatial and temporal infiltration dynamics during managed aquifer recharge. Ground Water 50, no. 4: 562-572. DOI: 10.1111/j.1745-6584.2011.00875.x. http://www.ncbi.nlm.nih.gov/pubmed/22050208.

Ruehl, C., A. Fisher, C. Hatch, M. Los Huertos, G. Stemler, and C. Shennan. 2006. Differential gauging and tracer tests resolve seepage fluxes in a strongly-losing stream. Journal of Hydrology 330, no. 1-2: 235-248.

Saraf, A.K., and P.R. Choudhury. 1998. Integrated remote sensing and GIS for groundwater exploration and identification of artificial recharge sites. International Journal of Remote Sensing 19, no. 10: 1825-1841. http://www.tandfonline. com/doi/abs/10.1080/014311698215018.

Schmid, W., and R.T. Hanson. 2009. The farm process version 2 (FMP2) for MODFLOW-2005-Modifications and upgrades to FMP1. U.S. Geological Survey Techniques and Methods 6-A-32, 102 P. Reston, Virginia: USGS.

Schmidt, C.M., A.T. Fisher, and A. Racz. 2011a. Rapid nutrient load reduction during infiltration of managed aquifer recharge in an agricultural groundwater basin: Pajaro Valley, California. Hydrological Processes. DOI: 10.1002/hyp. http://onlinelibrary.wiley.com/doi/10.1002/hyp.8320/full.

Schmidt, C.M., A.T. Fisher, A.J. Racz, B.S. Lockwood, and M. Los Huertos. 2011b. Linking denitrification and infiltration rates during managed groundwater recharge. Environmental Science \& Technology 45, no. 22: 9634-9640. DOI: 10.1021/es2023626. http://www.ncbi.nlm.nih.gov/ pubmed/21992590.

Shankar, M.N.R., and G. Mohan. 2005. A GIS based hydrogeomorphic approach for identification of site-specific artificial-recharge techniques in the Deccan Volcanic Province. Journal of Earth System Science 114, no. 5: 505-514.

Wallace, M., and B.S. Lockwood. 2009. Pajaro Valley Water Management Agency annual report. Watsonville, CA: Pajaro Valley Water Management Agency.

Yeh, H.-F., C.-H. Lee, K.-C. Hsu, and P.-H. Chang. 2009. GIS for the assessment of the groundwater recharge potential zone. Environmental Geology 58: 185-195. DOI: 10.1007/s00254-008-1504-9. http://www.springerlink.com/ index/J084553P55211151.pdf. 